\title{
Global Burden of Diabetes- Rising Expenditures on Healthcare Economy
}

\author{
Pradeep Kumar Dabla ${ }^{{ }^{*}}$, Vandana Dabla ${ }^{2}$ \\ ${ }^{1}$ Department of Biochemistry, G.B Pant Institute of Postgraduate Medical Education \& Research, Associated to Maulana Azad Medical College, \\ New Delhi, India \\ ${ }^{2}$ NISCHIT CDC-SHARE INDIA SHARE INDIA, MIMS Campus, Ghanpur Village, Medchal Mandal, Telangana, India
}

Received: November 03,2018; Accepted: November 10,2018; Published: November 13,2018

*Corresponding author: Pradeep Kumar Dabla, Department of Biochemistry, G.B Pant Institute of Postgraduate Medical Education \& Research, Associated to Maulana Azad Medical College, New Delhi, India. E-mail: pradeep_dabla@yahoo.com

\section{Abstract}

The dynamics of the diabetes epidemic are changing rapidly. It is a matter of concern on global scale from a public health perspective and also in relation to rising societal costs. Once a disease of the West, type 2 diabetes has now spread to every country in the world from affluence to poor.

The rising cost and ever increasing burden on health care resources to treat and monitor diabetes and its complications put a heavy financial and manpower burden on national health care systems. Asia's large population and rapid economic development have made it an epicenter of the epidemic. Asian populations tend to develop diabetes at younger ages and lower BMI levels than Caucasians. Interactions between Westernized diet and lifestyle and genetic background may accelerate the growth of diabetes in the context of rapid nutrition transition. This epidemic is primarily driven by rapid urbanization, nutrition transition, and increasingly sedentary lifestyles. It reflects affluence and exposure to increased calorie intake in combination with sedentary lifestyle and less human energy expenditure. However, primary prevention through changes in public policies, the food and built environments, health systems and promotion of a healthy diet and lifestyle should be a global public policy priority.

Keywords: Diabetes; Type 2 diabetes; T2DM; Obesity; Global epidemic; Financial burden; prevention; factors

\section{Core Tip}

Obesity and Type 2 diabetes pose a serious public health and economic threat for world. Cases of obesity and diabetes are increasing inevitably with impending costs to health and economic systems. World leaders need to set an example of successful innovative prevention and treatment programs, fully supported by all government stakeholders in partnership with private sector and civil society.

\section{Introduction}

Over the last 2 decades with the increasing industrialization and mechanization in today's world, the type 2 diabetes (T2DM) emerged as a global public health threat. Epidemiological studies have predicted that whereas 422 million subjects were affected by diabetes in 2014 , the coming decades may see an astonishing 438 million adults affected by 2030 The burden of diabetes has increased faster in low-income and middle-income countries in terms of both prevalence and rising number of adult patients. With increased international trade came an influx of fatty foods accessible to all. Technology such as computers and mobile devices led to less physical activity and contributed to weight gain. The tremendous cost of this diabetes epidemic can be counted not only in financial terms as cost of illness, treatment, and disability, but also in terms of the human cost of suffering and a lowered health related quality of life.

\section{Demographic overload}

Compared with Western populations, the prevalence of overweight and obesity in Asia is relatively low, but it is increasing proportionately. Though, rate of obesity is not directly proportional to diabetes. Asians develop diabetes at younger ages, at lower degrees of obesity, and at much higher rates. According to the Gallup-Healthways Well-Being Index, the obesity rate among American adults is $28 \%$, while diabetes tops $11 \%$. Nearly one in five smokes, two in five experience significant daily stress, and almost half do not exercise for 30 minutes or more at least three days per week. In Mexico, roughly a third of the population is now obese, and the proportion of obese children is the highest in the world. Type 2 diabetics in Mexico are expected to double in number by 2050 . Asia accounts for $60 \%$ of the world's diabetic population due to rapid economic development, urbanization, and transitions in nutritional status. This led to an explosive increase in diabetes prevalence within a relatively short time. In India as well, obesity has surged, and children are afflicted in both urban and poor rural areas. India's Type 2 diabetes rate is 10 times what it was in the 1970 s, and by 2030 there are expected to be 100 million diabetics. In China, more than 120 million people are now obese; its diabetic population is the largest in the world.

\section{Contributing Factors}

Considerably there are number of factors with health consequences. Overweight and obesity are driving the global 
diabetes epidemic. They affect the majority of adults in most developed countries and are increasing rapidly in developing countries. Then, the aging of many populations, with an increasing proportion of elderly people, will contribute to the growing number of subjects reaching the age ranges where T2DM becomes more prevalent. Further, the detrimental lifestyle changes that is now characteristic of not only Western populations, but also to a substantial proportion of populations in developing countries. These all added by passive lifestyle related to sedentary leisure activities, such as watching television or time spent on the computer. Another contributing risk factor is smoking and alcohol, now very prevalent in developing countries as well. American adults who smoke, spends on an average \$2,132 more each year in healthcare costs compared to nonsmokers. Overweight or obese Americans who smoke add an astonishing $\$ 235$ billion in unnecessary healthcare costs each year. Additional factors include selected diet containing more of coffee, alcohol, sucrose, and saturated fat with lack of vitamins, vegetables, and fruits.

\section{Healthcare cost}

Human suffering and reduced health-related quality of life are an additional burden with ever increasing healthcare cost of globalization for the growing epidemic of T2DM. Cases of obesity and diabetes will inevitably increase and debilitate costs to these nations' health and economic systems. Diabetes among American adults is estimated to cost the U.S. economy an additional $\$ 245.5$ billion in 2017 in total healthcare expenditures. Above-normalweight adults in the U.S. add more than $\$ 142$ billion each year in incremental healthcare costs. By the early 2000s, several nongovernmental organizations, such as the Brazilian Association of Nutrition and the Brazilian Diabetes Society, began to pressure the ministry to adopt supportive legislation. In Mexico, obesity and its associated diseases cost the government's health care system between $\$ 4.3$ billion and $\$ 5.4$ billion a year. Costs for diabetes programs and treatment rose from $\$ 318$ million in 2005 to $\$ 343$ million in 2010 whereas $\$ 4$ billion were spent on diabetes related diseases in 2012.

Indian government expenditures on Type 2 diabetes patients ranged from $\$ 25$ billion to $\$ 38$ billion in 2010, mostly on medication and hospitalization which is expected to increase roughly by $\$ 237$ billion during next decade. In China, in 2009, the government is estimated to have spent $\$ 3.5$ billion treating obese patients. Recent studies estimates $\$ 25$ billion a year, and it's expected to reach $\$ 47$ billion by 2030 . Christian Bommer and colleagues estimated that global economic burden will increase from U.S. \$1.3 trillion in 2015 to $\$ 2.1$ trillion in the target scenarios by 2030 . This will lead to increase in costs as a global GDP from $1.8 \%$ in 2015 to a maximum of $2.2 \%$ in 2030.

\section{Conclusion}

Type 2 diabetes is a global crisis that threatens the health and economy. This epidemic is primarily driven by rapid urbanization, nutrition transition, and increasingly sedentary lifestyles. The diabetes epidemic in Asia is characterized by onset at lower BMI levels and younger ages. Importantly, primary prevention through the promotion of a healthy diet and lifestyle should be a universal policy. Policy makers with local governments need to implement preventive policy while learning from civil society how to improve health care services.

\section{Acknowledgement}

Dabla P. K \& Dabla V conceived the study and drafted the manuscript; authors approved the final version of the article.

\section{References}

1. International Diabetes Federation. IDF Diabetes Atlas. Epidemiology and Mobidity. In: International Diabetes Federation. 2018.

2. DAN W, SANGEETA A, Obesity, Smoking Damage U.S. Economy. BUSINESS JOURNAL. 2016.

3. Barquera SI. Campos and JA Rivera. "Mexico Attempts to Tackle Obesity: The Process, Results, and Push Backs and Future Challenges." Obesity Reviews. 2013;14(2):69-78. Doi: 10.1111/obr.12096

4. Henson J, Dunstan DW, Davies MJ, Yates T. Sedentary behavior as a new behavioral target in the prevention and treatment of type 2 diabetes. Diabetes Metab Res Rev. 2016;32(suppl 1):213-220. Doi: 10.1002/ dmrr.2759

5. Fernandes SD, Sunny DA Fernandes. Economic burden of diabetes mellitus and its socio-economic impact on household expenditure in an urban slum area. Int J Res Med Sci. 2017;5(5):1808-1813. Doi: 10.18203/2320-6012.ijrms20171585

6. Kanguru L, Bezawada N, Hussein J, Bell J. The burden of diabetes mellitus during pregnancy in low- and middleincome countries: a systematic review. Glob Health Action. 2014;7:23987. Doi: 10.3402/ gha.v7.23987

7. Chan JC, Malik V, Jia W, Kadowaki T, Yajnik CS, Yoon KH, et al. Diabetes in Asia: epidemiology, risk factors, and pathophysiology. JAMA. 2009;301(20):2129-2140. Doi: 10.1001/jama.2009.726

8. Wang Y, Mi J, Shan XY, Wang QJ, Ge KY. Is China facing an obesity epidemic and the consequences? The trends in obesity and chronic disease in China. Int J Obes (Lond) 2007;31(1):177-188. Doi: 10.1038/ sj.ijo.0803354

9. Bommer C, Sagalova V, Heesemann E, Manne-Goehler J, Atun R, Bärnighausen T, et al. Global Economic Burden of Diabetes in Adults: Projections From 2015 to 2030. Diabetes Care. 2018;41(5):963-970. Doi: $10.2337 / \mathrm{dc} 17-1962$ 